Running Head: CALL \& MALL

CALL \& MALL: The New Age Language Learning

Manisha Sen

Department of Electronics and Communication Engineering Institute of Engineering and Management 


\begin{abstract}
Technology changes rapidly and it holds visible effects in many spheres of our lives including education. CALL (Computer Assisted Learning Language) is a popular term and has been in use since 1960s or 1970s. However MALL (Mobile Assisted Learning Language) is a relatively new term and is being used for the past one or two decades. Computer on one hand has ability to handle good amount of information: audio-visual or textual while mobile phones are superior in terms of portability. This paper aims at providing information about CALL and MALL related technology resources and the ways in which these promote fruitful education.
\end{abstract}

Keywords: Computer Assisted Language-Learning (CALL), Mobile Assisted Language- Learning (MALL), live language teacher 


\section{Technology Assisted Language Learning}

The only means of learning was the blackboard, chalk and books not too long ago. With the advancement of technology (computers and mobile phones), language classrooms have benefited a lot and language labs got a new lease on life. CALL had been an area of educational research from a long time. [3] Computers have been the most significant product in the realm of education. "CALL means learners learning language in any way with, through, and around computer technologies," Egbert (2005) said. MALL is an emerging field with its new way of learning and expanding educational boundaries through mobility. MALL involves the use of mobile devices like smartphones, pads, pods, Personal Digital Assistants (PDAs) for language learning. [1]

In addition to promoting the level of teaching, the effective implementation of modern technologies in educational and pedagogical practices also motivates learners through innovative and attractive learning modules. The proper use of mobile and computer related technology in and outside the classroom improves the process of teaching and learning and allows students to understand the language better by developing information and awareness with additional information and interest. Teaching-learning, unlike conventional and even some modern classroom teaching, this new technology has eliminated the major time and location constraints, paving the way for learners of all age groups to have more personalized, coordinated and interactive learning experiences. [4]

\section{Present Scenario and Future Prospects of Technology Assisted Language Learning in India}

Currently, India has the second highest number of smartphone users in the world, the first one being China. According to a report published by the Indian Express (July 2020), the number of smartphone consequently those with access to internet in phones users in India is likely to rise to 83 crores in 2022. Moreover it also mentioned that smartphone penetration in rural India has risen from 9 per cent in 2015 
to 25 per cent in 2018. This diffusion of technology and the internet should be accompanied by the adequate level of expertise and skills necessary for the handling of technical equipment for learning purposes.

Keeping an eye on the survey, in India the future of CALL and MALL looks quite promising in semiurban areas. However, the situation in rural areas, while improving, is not quite satisfactory so far due to a lack of basic infrastructure and technical accessibility. In order to increase the reach of CALL and MALL, infrastructure reinforcement in rural and remote areas is therefore very necessary. [4]

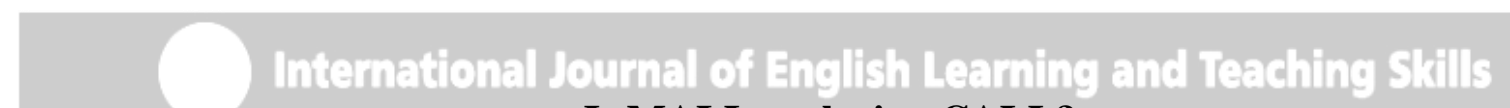

\section{Is MALL replacing CALL?}

Warschauer (1996) divides the evolution of CALL into three phases: Behavioristic CALL (1960s1970s), Communicative CALL (1970s-1980s), and Integrative CALL (1990s-till date).

The phase valid today is Integrative CALL. It is mostly web-based and gives computers and internet a facilitator role. As Bax (2003) stresses, CALL has gone through considerable changes over time. With the advancement of mobile devices like smart phones, MALL has emerged as a new dimension in the field of Technology Enhanced Language Learning (TELL).

A question arises as to whether MALL will replace CALL or complement it. Although they are not direct alternatives to each other they both aim to help language learners to enhance their skills to a desirable extent in different ways.[1] However with time MALL is becoming increasingly popular due to the following reasons:

i. Short messages and photography.

ii. Audio and video photography for playback of music and ringtones.

iii. Individual and interactive games and access to information (such as driving directions, travel information, and email) [2]

iv. Smaller size and portability 
Running Head: CALL \& MALL

Moreover CALL has certain restrictions which are:

i. Access to computers or internet is not possible in everywhere (digital divide)

ii. Feeling of artificiality

iii. Distracting elements

However small screen and limited data storage can be two disadvantages possessed by MALL. Smartphones are also becoming one of the most popular cheating tools [1] hence CALL cannot be replaced by MALL but can only complement it.

\section{International Jounal of English leaming and Teaching Shills}

\section{Are CALL and MALL replacing the live language teacher?}

It cannot be claimed that technology won't have a space in language learning and indeed it has provided invaluable benefits for both teachers and students. Language mostly involves communication in flesh and blood. Therefore, the role of the live language teacher cannot be denied.

Asynchronous sessions are assisted by synchronous ones, also in distance language education, to improve instant student-teacher and student-student interaction since

“...the key to successful use of technology in language teaching lies not in hardware or software but in 'humanware' - our human capacity as teachers to plan, design and implement effective educational activity" (Warschauer \& Meskill, 2000, p. 316).[1] Although CALL and MALL will gain popularity, the role of live language teachers cannot be wiped out entirely. 


\section{Conclusion}

In every aspect of our lives, technology plays a visible role and its role in language learning cannot be denied; it will make students smarter and help them learn faster. Technology, as Warschauer said in 2009, should not be treated as "a magic bullet to solve educational problems, but rather as a powerful weapon that can have both positive and negative consequences and that must be carefully utilised." [1]. The role of language teachers is critical because they are responsible for managing the resources provided by CALL and MALL and directing students in the right direction to achieve a pre-established educational objective.

Intemational Jounal of Enellish Leaming and Teaching Shills

[1] Ismail Yaman and Emarh Ekmekci, A Shift from CALL to MALL, English Language Learning Programme, Samsun, Turkey

[2] K. E. Valarmathi, Mobile Assisted Language Learning, Journal of Technology for ELT - Vol II. No. 2 (April 2011)

[3] Junia de Carvalho Fidelis Braga ,Luciana de Oliveira Silva ,Ronaldo Correa Gomes Junior ,CALL \& MALL: using technology to achieve educational objectives in the language classroom, Inspiring Insights from English Teaching

[4] Subodh N. Chinchole, Mobile Assisted Language Learning: Scope and Limitations in Rural and Semi-urban Indian Context, Language in India ISSN 1930-2940 Vol. 19:8 August 2019 